\title{
Gender differences in sore throat and hoarseness following endotracheal tube or laryngeal mask airway: a prospective study
}

Maria Jaensson ${ }^{1,2^{*}}$, Anil Gupta $^{1 \dagger}$ and Ulrica Nilsson ${ }^{2 \dagger}$

\begin{abstract}
Background: Postoperative sore throat and hoarseness are common minor complications following airway manipulation. This study was primarily done to determine gender differences in the incidence of these symptoms and the location of POST after laryngeal mask airway (LMA) and endotracheal tube (ETT).

Methods: A total of 112 men and 185 women were included during a four month period. All patients were evaluated postoperatively and after 24 hours about the occurrence of sore throat, its location and hoarseness. If the patients had any symptom, they were followed-up at 48, 72 and 96 hours until the symptoms resolved.

Results: There was no significant gender difference in postoperative sore throat (POST) and postoperative hoarseness $(\mathrm{PH})$ when analyzing both airway devices together. The incidence of sore throat and hoarseness were higher postoperatively after an ETT than an LMA (32\% vs. 19\%, $p=0.012)$ and $57 \%$ vs. $33 \%(p<0.001)$ respectively. Significantly more women than men had POST after an LMA ( $26 \%$ vs. $6 \%, p=0.004)$. No significant gender difference was found in either POST or PH after an ETT or in the incidence of PH after an LMA. More patients located their pain below the larynx after an ETT vs. an LMA (24\% vs. 4\%). Pain above the larynx was more common after an LMA than an ETT (52\% vs. 37\%).

Conclusions: In a clinical setting where women are intubated with a smaller size ETT than men, there were no significant differences in POST or PH between genders. Additionally, more women than men have POST when an LMA is used. Awareness of POST and PH may help streamline patients in whom the best airway device could be used during anesthesia and surgery.
\end{abstract}

Keywords: Sore throat, Hoarseness, Endotracheal tube, Laryngeal mask airway, Postoperative complications

\section{Background}

Postoperative sore throat (POST) and hoarseness $(\mathrm{PH})$ after general anaesthesia are common but minor adverse events after endotracheal intubation (ETT) and laryngeal mask airway (LMA). A systematic review found a lower incidence of airway morbidity following the use of an LMA compared to an ETT [1].

Previous studies have shown that women are at a greater risk for POST compared to men after an ETT [2-4]. There is no consensus in the literature today as to what constitutes POST, and how or when it should be

\footnotetext{
* Correspondence: maria.jaensson@oru.se

${ }^{\dagger}$ Equal contributors

'Division of Anaesthesiology and Intensive Care, Örebro University Hospital, Örebro, Sweden

${ }^{2}$ Schools of Health and Medical Sciences, Örebro University, Örebro, Sweden
}

measured [2,5-7]. Therefore, the results between studies may not be comparable [8]. Another contributing factor towards the variation in results could be that different ETT sizes have been used in women: size number 6.5 [4], number 7.0 [9] or 7.5 [2] while some authors do not state what ETT size was used [3]. Since patient satisfaction with anaesthesia may be further improved by reducing the risk of POST and PH $[10,11]$ the symptoms needs to be continuously re-evaluated in different settings. The appropriate ETT size in women and men is still unclear and debated in the anesthesia community [12]. However, there seems to be some evidence that women benefit from a smaller size ETT [13]. The etiology of POST is also not clearly understood, but it appears to be an inflammatory process since the tracheal 
mucosa has been found to release inflammatory mediators after intubation [14]. However, the exact anatomical location of sore throat still remains uncertain in patients [8]. Although the evidence points towards female gender as a risk factor for POST, there have been few studies evaluating the difference between genders in recent years [15].Therefore we sought to determine if there are any gender differences in relation to the incidence of sore throat and hoarseness following endotracheal intubation and laryngeal mask airway.

This study was done with the primary aim to determine if there is a gender difference in the incidence and location of postoperative sore throat, and for the incidence of hoarseness after a laryngeal mask airway and endotracheal tube. We also determined the duration or persistence of these symptoms.

\section{Method}

This investigation was a non-randomized, prospective and longitudinal study performed at the Örebro University Hospital, Sweden. After approval from Regional Ethics committee in Uppsala, Sweden (nr. 2012/392), informed written and verbal consent were obtained from all patients. The patients were either inpatients or ambulatory patients.

The inclusion criteria were: age $>18$ years, elective surgery with either a laryngeal mask airway or endotracheal tube. The exclusion criteria were: surgery in the mouth or throat area, nasal intubation, the use of oesophageal probe, ongoing upper airway infection and expected duration of surgery $>240$ minutes.

\section{Anaesthesia}

The anaesthesia protocol followed hospital routines and could include maintenance of anaesthesia using either target- controlled infusion (TCI) with propofol and remifentanil or inhalation anesthesia with sevorane or desflurane in oxygen and air. Standard monitoring included oxygen saturation, heart rate, non- invasive blood pressure, end-tidal carbon dioxide concentration, bispectral index in patients having TCI and neuro- muscular transmission monitoring in patients given musclerelaxant. The ETT used in this study was Mallinckrodt Hi-Contour $^{\text {TM }}$ (Mallinckrodt, Athlone, Ireland) while a disposable LMA (Unique ${ }^{\mathrm{Tm}}$, Shanghai, China) was used in almost all cases, except in a few patients where a nondisposable Proseal (Seychelles) was used.

\section{Insertion of the laryngeal mask airway and endotracheal intubation}

The insertion technique for the LMA was left to the discretion of the personnel using the device. A water-based lubricant (Glidslem APL, Stockholm, Sweden) was used on the posterior and lateral surfaces of the LMA cuff but not on the ETT cuff. Air was used to ensure adequate sealing of the cuff using existing hospital routines so that the cuff pressure was maintained at $20-30 \mathrm{~cm}$ $\mathrm{H}_{2} \mathrm{O}$ in an ETT [16] and at $30-60 \mathrm{~cm} \mathrm{H}_{2} \mathrm{O}$ in the LMA [17]. Cuff pressure was measured continuously during surgery and documented regularly in the anaesthesia chart.

\section{Measurement and recordings}

In addition to recording the included patient's age, height and weight, and the type of surgery, the following additional measurements were made: anaesthesia experience of the anaesthetist (years) and insertion technique (LMA cuff inflated or partially deflated). Furthermore, ease of LMA insertion was graded into easy (one attempt, no tactile resistance), some difficulty (one attempt but tactile resistance) and difficult (two or more attempts) [18]. Finally, the number of attempted laryngoscopies (one, two or $\geq$ three), the use of extra airway management equipment during intubation (stylet or video laryngoscope), and fixation of the ETT (left or right cheek, or in the middle of the mouth) were also recorded. Drugs that were administered during anaesthesia and that may affect POST or $\mathrm{PH}$ such as non-depolarizing or depolarizing muscle relaxant, cortisone, opioids and non-steroidal antiinflammatory drug were also recorded.

\section{Procedure}

One of the authors (MJ) or the research nurses performed the follow-up questions. Standardized questions were presented to the patients and data collected from all patients in the post-anaesthesia care unit (PACU), and 24 hours after extubation. The 24 hour follow- up of inpatients was performed in the ward while ambulatory surgery patients were interviewed by a telephone call. If the patient reported any symptom at 24 hours, assessment was done once each day at 48, 72 and 96 hours until the patients were symptom-free. The patients were asked if POST was present at rest, which was defined as constant pain in the throat, or if POST increased on swallowing or talking?

Patients having symptoms for longer than 96 hours were offered telephone advice by an anaesthesiologist. If the patient had symptoms at 96 hours, a follow-up call was made after five to seven days by one of the investigators (MJ).

\section{Postoperative sore throat and hoarseness}

The scale used to evaluate POST was a four graded scale: $0=$ No sore throat, $1=$ Mild sore throat (less than with a cold), 2 = Moderate sore throat (as with a cold) and 3 = Severe sore throat (more severe than with a cold) [7]. PH was scored as: $0=$ No hoarseness, $1=$ Mild hoarseness (noticed by the patient only), 2 = Severe 
hoarseness (noticed at the time of the interview by the personnel) and 3 =Aphonia (inability to speak) [19]. Both scales are thought to be reliable and have been used in several studies [15,20-22].

An open-ended question was also used to assess POST: "Can you describe the symptom in your own words".

\section{Location of postoperative sore throat}

The patients assessed the location of sore throat in the PACU and at 24 hours follow up, using a photograph showing the exterior and interior of the throat and mouth in the following way: 1 = in the mouth, $2=$ in the pharynx, 3 = above larynx, 4 = below larynx, $5=$ high up in the chest (Figure 1). Verbal and written consent were obtained to publish the photographs of the persons included.

\section{Statistics}

A priori sample size was decided after reviewing the literature. The studies available were not consistent in

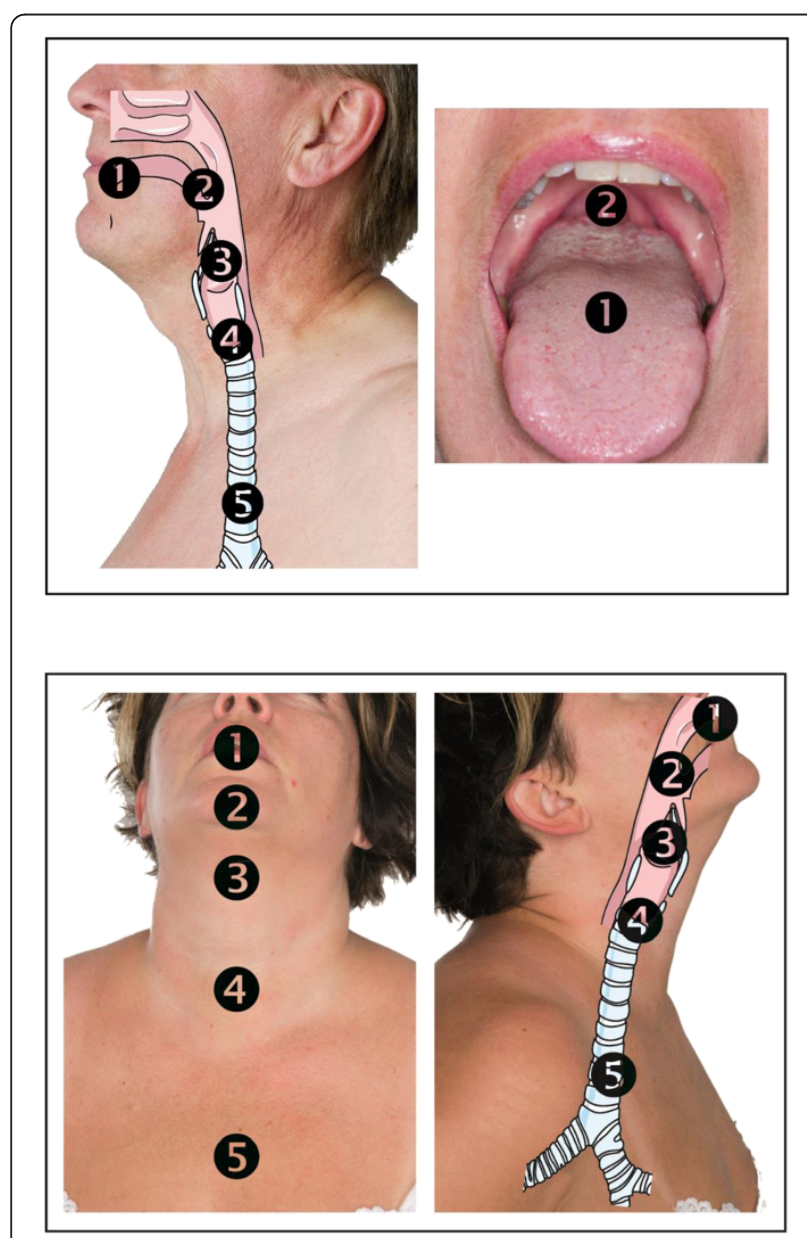

Figure 1 A two-sided laminated photograph for localization of the sore throat $\odot$. reporting the incidence of POST and potential differences between the sexes after an LMA [18,23-25] or an ETT $[2,7,26$,$] . From these studies, we determined that$ the incidence of POST at the PACU was $40 \%$ when all airway devices were pooled together. Our hypothesis was that men have a lower incidence of POST, approximately $20 \%$ (absolute difference $=20 \%$ ). Assuming a power of $80 \%$ and a significance level of 0.05 we determined that 91 patients would be needed/group. The study was also set to be ongoing for four months. Uniand bi- variate analyses between gender and subgroup analysis between LMA and ETT were performed. In order to test for normal distribution, a one sample Kolmogorov Smirnov analysis was used. For comparison of demographic data and analgesic consumption the Student's $t$ - test or Mann-Whitney $U$ test was used as appropriate. Differences between groups for dichotomous data were analyzed using the Chi-square-test or the Fisher's exact test. All statistical analyses were performed with SPSS 17.0 for windows software (SPSS Inc. Chicago, IL, USA). P $<0.05$ was considered statistically significant.

\section{Results}

During the period January to April 2013 a total of 301 patients, (men $\mathrm{n}=115$ and women $\mathrm{n}=186$ ) from five different surgical departments (Urology, General-, Orthopedic-, Gynecological- and Hand- surgery) were consecutively screened and enrolled in the study. Four patients were subsequently excluded from the analysis since they had both an LMA and an ETT during anaesthesia. In one man, several unsuccessful attempts were made to insert a Proseal LMA and he was subsequently intubated. Two men and one woman had to be intubated during surgery because of in adequate ventilation when using an LMA. Therefore, a total of 297 patients were included in the final analysis (Figure 2). Men weighed more $(\mathrm{p}<0.001)$ and were taller $(\mathrm{p}<0.001)$ and required more intraoperative fentanyl $(p=0.008)$. There were no gender differences in morphine and ketobemidone consumption at the PACU (Table 1).

The number of attempts needed to intubate men and women respectively were as follows: one attempt in 32 (29\%) and 72 (39\%), two attempts in 21 (19\%) and 15 (8\%) and three or more attempts in $6(6 \%)$ and $0(\mathrm{p}=$ 0.002). A stylet was used to aid insertion in more men compared to women 12 vs. 7 ( $63 \%$ vs. $32 \%$; $p=0.017$ ) .

The LMA was used in 134 (91\%) and Pro Seal in 13 (9\%) of patients. The registered nurse anaesthetist or anaesthesiologist chose the size of LMA from personal experience and using the guidelines recommended by the manufacturers. There were no gender differences in how the LMA was inserted i.e. with the cuff partially inflated or deflated cuff ( $p=0.3$ ). Rotation of the LMA during insertion was more common in men $(p=0.001)$. The LMA 


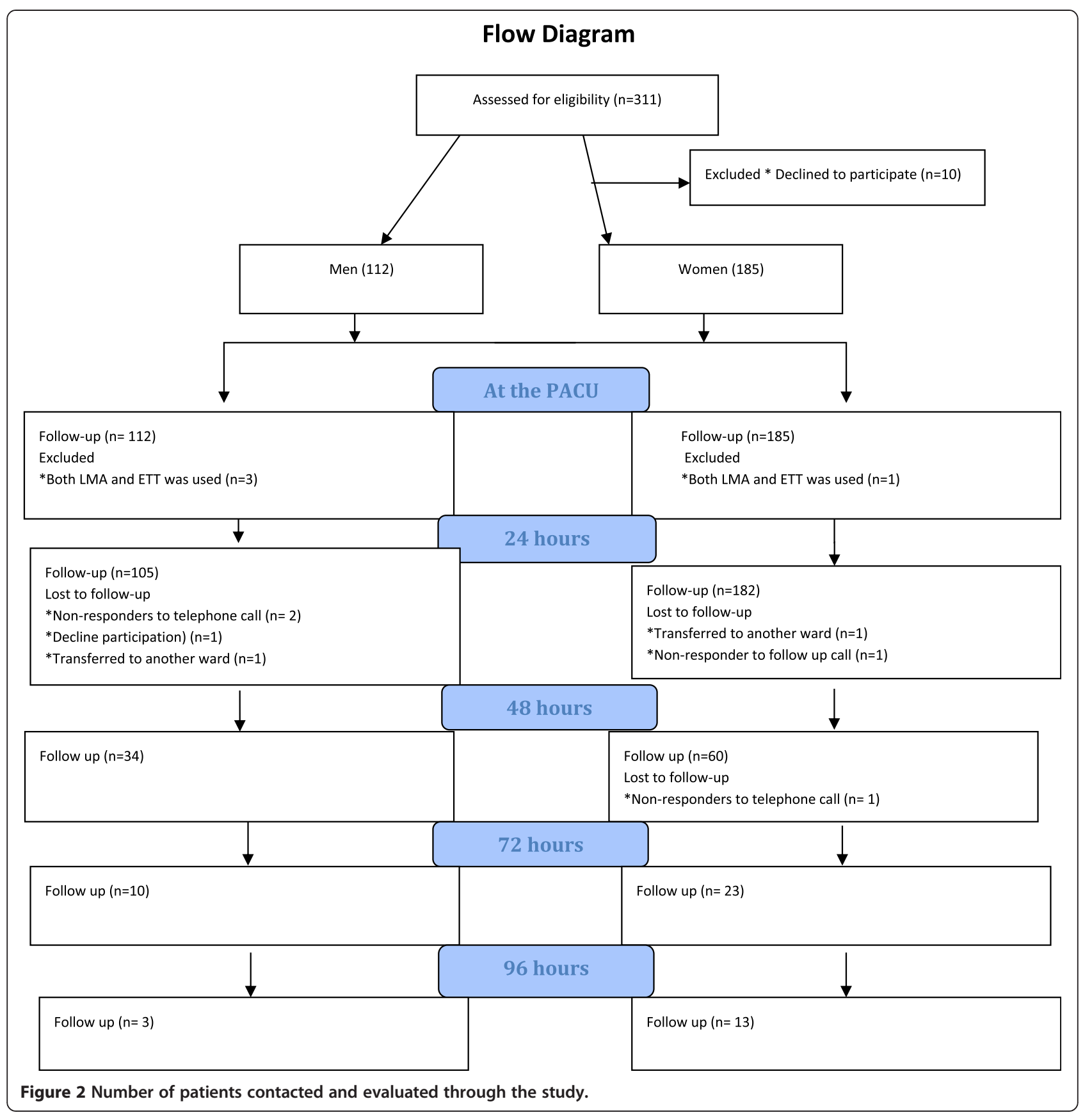

insertion was graded in women as follows; easy $82 \%$ $(\mathrm{n}=77)$, some difficulty $15 \%(\mathrm{n}=14)$ and difficult $3 \%$ $(\mathrm{n}=3)$. Corresponding values for men were, easy $80 \%$ $(\mathrm{n}=41)$, some difficulty $12 \%(\mathrm{n}=6)$ and difficult $8 \%(\mathrm{n}=4)$. Even though insertion was considered easy, more women had POST compared to men $(p=0.07)$. Irrespective of airway device (ETT or LMA) used there were no significant gender difference in POST or PH at the PACU. When stratified for different surgical departments, irrespective of airway device, there were more women who had POST after hand-, orthopedic-, gynecology and general surgery. However, more men had POST after urology surgery. There were no significant differences between women and men after an ETT (27\% vs. $38 \%, \mathrm{p}=0.2)$. However, there were more women than men who had POST after an LMA ( $26 \%$ vs. $6 \%, \mathrm{p}=0.004)$. If the Proseal LMA was removed from the analysis there were more women than men who had POST ( $24 \%$ vs. $5 \%$, $\mathrm{p}=0.004)$ and there were no significant difference in $\mathrm{PH}$ between genders. More women $(n=11)$ than men $(n=1)$ said that POST was present during swallowing after an LMA (Table 2). There were no significant differences in 
Table 1 Patients characteristics and demographic data

\begin{tabular}{|c|c|c|c|}
\hline & $\begin{array}{l}\text { Men } \\
(n=112)\end{array}$ & $\begin{array}{l}\text { Women } \\
(n=185)\end{array}$ & P-value \\
\hline \multicolumn{4}{|l|}{ Patient characteristics } \\
\hline Age(yr) & $56(16)$ & $53(18)$ & $p=0.85^{\Omega}$ \\
\hline ASA I/II/III n (\%) & $\begin{array}{l}50(45) / 50(45) / \\
11(10)\end{array}$ & $\begin{array}{l}85(46) / 91(49) / \\
8(0.5)\end{array}$ & $p=0.3^{\infty}$ \\
\hline Height (cm) & $179(7)$ & $165(6)$ & $p=<0.001^{\Omega}$ \\
\hline Weight (kg) & $87(16)$ & $71(14)$ & $p=<0.001^{\Omega}$ \\
\hline \multicolumn{4}{|l|}{$\begin{array}{l}\text { Perioperative } \\
\text { medications }\end{array}$} \\
\hline Rocuronium & $52(24)$ & $42(17)$ & $p<0.001 \S$ \\
\hline Fentanyl & $157(86)$ & $127(100)$ & $p=0.008 \S$ \\
\hline Remifentanil & $34(195)$ & 136(359) & $p<0.001 \S$ \\
\hline Ketobemidon & $0.08(0)$ & $0.7(0)$ & $p<0.001 \S$ \\
\hline Bethametasone & $0.4(1.3)$ & $2(2.3)$ & $p<0.001 \S$ \\
\hline Morphine at the PACU & $4.8(16)$ & $1.9(3.5)$ & NS \\
\hline Ketobemidon at the PACU & $3(16)$ & $0.5(1.5)$ & NS \\
\hline \multicolumn{4}{|l|}{$\begin{array}{l}\text { Perioperative } \\
\text { characteristics }\end{array}$} \\
\hline Hand Surgery n (\%) & $19(17)$ & $20(11)$ & \\
\hline General Surgery n (\%) & $23(20)$ & $65(35)$ & \\
\hline Gynaecology n (\%) & & $44(24)$ & \\
\hline Orthopaedics n (\%) & $35(31)$ & $48(26)$ & \\
\hline Urology n (\%) & $35(31)$ & $8(4)$ & \\
\hline Daysurgery/Inpatients n (\%) & $55(49) / 57(51)$ & 107(58)/78(42) & $p=0.1^{\infty}$ \\
\hline Duration of surgery (min) & $67(10-203)^{*}$ & $59(6-234)^{*}$ & $p=0.02^{\S}$ \\
\hline ETT size 6.0/7.0/8.0 n(\%) & 0/2(3)/59(97) & $78(89) / 10(11) / 0$ & NA \\
\hline LMA size 3/4/5 n(\%) & 0/1(2)/50(98) & $5(5) / 92(95) / 0$ & NA \\
\hline Blood on the device n(\%) & $8(7)$ & $9(5)$ & $p=0.5^{\infty}$ \\
\hline $\begin{array}{l}\text { Experience of the } \\
\text { anaesthesia staff (yr) }\end{array}$ & $6(0-39)^{*}$ & $4(0-39)^{*}$ & $p=0.1^{\S}$ \\
\hline Time at the PACU (min) & $180(60-2160)^{*}$ & 192(45-620) & $p=0.7^{\S}$ \\
\hline
\end{tabular}

All results are presented as mean (SD) and median (range)*. Analyzed with the Mann-Whitney U -test ${ }^{\zeta .}$ Analysed with Chi-square ${ }^{\infty}$. Analysed with Students T-test ${ }^{\Omega}$. PACU $=$ Postanaeshesia care unit. LMA $=$ Laryngeal mask airway. $\mathrm{ETT}=$ Endotracheal tube. $\mathrm{NA}=$ Not applicable.

PH after either an ETT or an LMA between men and women. There was a higher incidence of POST in the ETT group compared to the LMA group (32\% vs. 19\%, $\mathrm{p}=0.012)$ as well as a higher incidence of $\mathrm{PH}$ in the ETT group compared to the LMA group ( $57 \%$ vs. $33 \%$, p < 0.001 ) in the PACU.

\section{Location of POST}

There were no significant differences between genders in location of POST after an ETT. Of those patients who reported pain in the PACU, the location of the sore throat was below the larynx after an ETT in 24\% $(n=11)$ vs. $4 \%(n=1)$ after an LMA. In patients with sore throat
Table 2 Pain in the throat

\begin{tabular}{|c|c|c|c|c|}
\hline & \multicolumn{2}{|c|}{ In the PACU } & \multicolumn{2}{|c|}{ After 24 hours } \\
\hline & LMA & ETT & LMA & ETT \\
\hline & $(n=24)$ & $(n=45)$ & $\left(n=18^{*}\right)$ & $\left(n=33^{* *}\right)$ \\
\hline Pain during rest & 0 & $1(2)$ & $1(5)$ & 0 \\
\hline Men/Women (n) & & $0 / 1$ & $0 / 1$ & \\
\hline Pain during speech & $1(4)$ & 0 & 0 & 0 \\
\hline Men/Women (n) & $1 / 0$ & & & \\
\hline Pain during swallowing & $12(50)$ & $12(27)$ & 7(39) & $14(42)$ \\
\hline Men/Women (n) & $1 / 11$ & $7 / 5$ & $0 / 7$ & $9 / 5$ \\
\hline $\begin{array}{l}\text { Pain at rest, during speech, } \\
\text { and swallowing }\end{array}$ & $9(38)$ & $19(42)$ & $7(39)$ & $12(36)$ \\
\hline Men/Women (n) & $1 / 8$ & $10 / 9$ & $3 / 4$ & $6 / 6$ \\
\hline $\begin{array}{l}\text { Pain during speech and } \\
\text { swallowing }\end{array}$ & 2(8) & $8(18)$ & $3(17)$ & $5(15)$ \\
\hline Men/Women (n) & $0 / 2$ & $4 / 4$ & $0 / 3$ & $0 / 5$ \\
\hline Pain at rest and during speech & 0 & $3(6)$ & 0 & 0 \\
\hline Men/Women (n) & & $1 / 2$ & & \\
\hline Pain at rest and during swallow & 0 & $2(4)$ & 0 & $2(6)$ \\
\hline Men/Women (n) & & $1 / 1$ & & $0 / 2$ \\
\hline
\end{tabular}

Presented as $\mathrm{n}(\%) .{ }^{*}$ Two missing. ${ }^{* *}$ One missing.

$\mathrm{LMA}=$ Laryngeal Mask Airway. $\mathrm{ETT}=$ Endotracheal tube. $\mathrm{PACU}=$ Post Anaesthesia Care Unit.

above the larynx, the distribution of symptoms between ETT vs. LMA was as follows: in the pharynx, 22\% $(\mathrm{n}=10)$ vs. $37 \%(\mathrm{n}=10)$, above the larynx, 37\% $(\mathrm{n}=17)$ vs. $52 \%(\mathrm{n}=14)$ and finally top of the chest, $2 \%(\mathrm{n}=1)$ vs. $4 \%(\mathrm{n}=1)$ respectively. A few patients reported pain at two levels. In the pharynx and above the larynx after an ETT vs. LMA, $11 \%(\mathrm{n}=5)$ vs. $4 \%(\mathrm{n}=1)$ and above and below the larynx in $4 \%(n=2)$ patients who had an ETT.

When the patients were asked to describe the feeling in their throat in the PACU the most common words used were: dryness in the throat, feels like a cold, burning pain, irritation or tenderness and a swollen feeling.

\section{Follow-up}

Irrespective of airway device used there were no significant gender differences at any time during follow up. Also, there were no significant gender differences in remaining symptom of either POST or PH after an LMA (Figure 3), and no significant gender differences after an intubation, except during 72 hours- follow up when significantly more women had POST or $\mathrm{PH}(\mathrm{p}=$ 0.04) (Figure 4).

\section{Discussion}

Our main findings were that no statistically significant differences in POST and $\mathrm{PH}$ were found, irrespective of gender (male or female) or type of airway used (LMA or ETT). This shows that postoperative sore throat and 


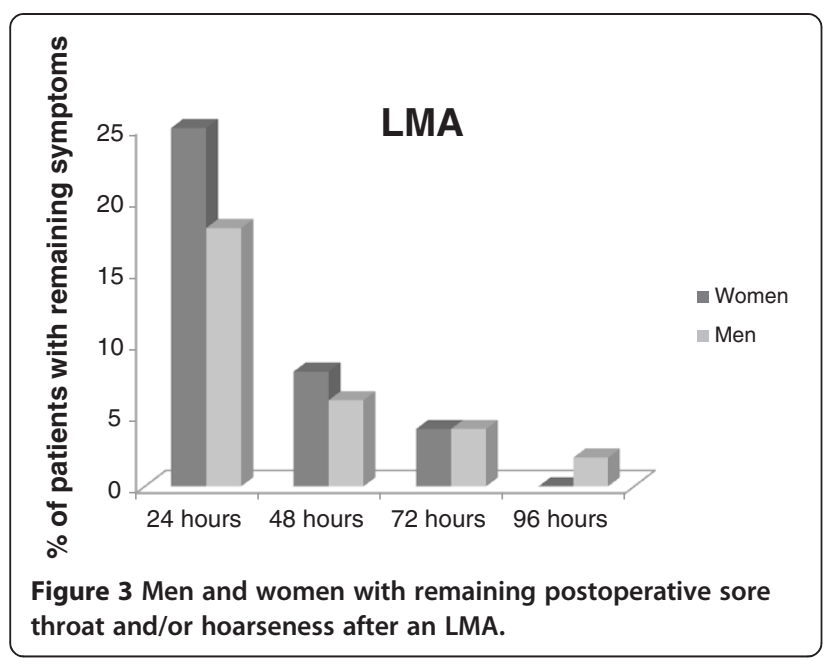

hoarseness are a concern for the patient regardless of whether an ETT or an LMA was used. Also, there were no significant gender differences in POST after an ETT. However, more women had POST after an LMA than men. Finally, no statistically significant differences in $\mathrm{PH}$ were found between genders or the type of airway used.

This study is one of few studies that did not find any gender differences in POST after an ETT $[15,26]$. One reason for this finding could be that there is some evidence in the literature that a smaller sized ETT in women decreases POST $[12,27,28]$. In our present study, most women had a small ETT, which may consequently have reduced the incidence of POST in women. However, we did find that women have more POST after an LMA than men, which confirms the findings of Nott et al. [25], but not Grady et al. [24] who found that men and women had a similar incidence of POST (20\%). The low incidence of POST in men in our study compared to the other studies raises questions as to why men and women respond differently to a standard LMA. Despite the manufacturers recommendation many anaesthetists

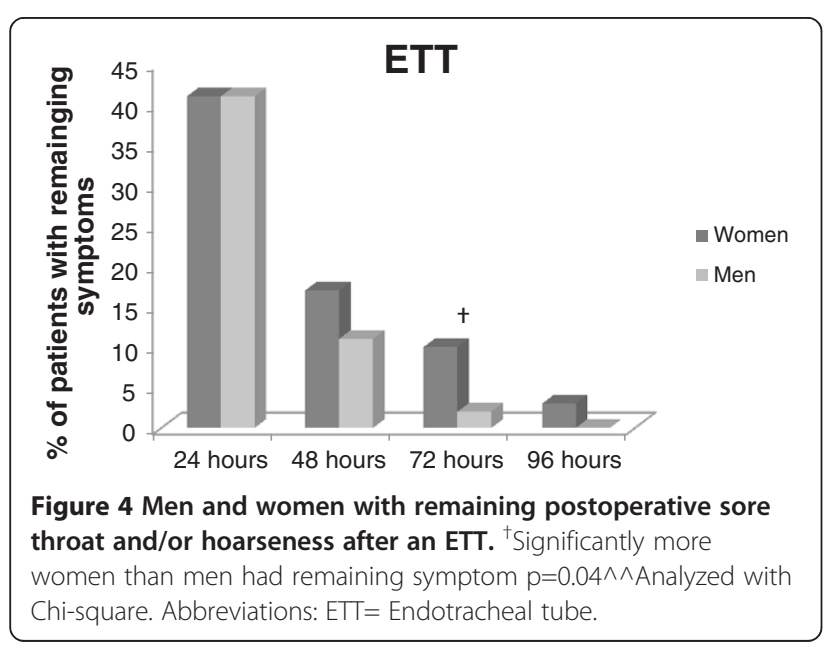

inserted the LMA with a partially inflated cuff. Having said this, earlier studies have not confirmed that the insertion technique is associated with POST $[29,30]$. The anatomy of the pharynx differs between the sexes [31] and it is possible that currently used LMAs are devised to better suit the anatomical features of the male pharynx rather than the female and therefore the lower incidence of POST in men. Another possible confounder in this study could be the wide range of cuff pressure in the LMAs. The reason for following the manufactures guidelines were because of the lack of consensus amongst researchers in an association between cuff pressure and POST. In the study by Burgard et al. [32], the cuff pressure in the control group was not adjusted during surgery and it became as high as $200 \mathrm{~cm} \mathrm{H}_{2} \mathrm{O}$ while the cuff pressure was held below $60 \mathrm{~cm} \mathrm{H} \mathrm{H}_{2} \mathrm{O}$ intra-operatively in the intervention group. However, in the study by Rieger et al. [33], there were no significant differences between intervention and the control group when the cuff pressure was at $30 \mathrm{mmHg}\left(41 \mathrm{~cm} \mathrm{H}_{2} \mathrm{O}\right)$ and $180 \mathrm{mmHg}\left(244 \mathrm{~cm} \mathrm{H}_{2} \mathrm{O}\right)$ respectively. A recently published study showed that a cuff pressure at $60 \mathrm{~cm} \mathrm{H}_{2} \mathrm{O}$ compared to $25 \mathrm{~cm} \mathrm{H}_{2} \mathrm{O}$ in LMA Supreme can increase pharyngolaryngeal adverse events. However, this study made no comparison between genders [34]. Although we used a smaller LMA in women than men, the anatomical formation of the LMA rather than its size may play an important role in the development of POST. We also found a higher incidence of $\mathrm{PH}$ in our patients after an LMA compared to the study by Yu et al. [1]. In one previous study, the authors suggest that $a$ larger LMA (size 5) may contribute to an increase in the frequency of PH in men. However, the LMA size (3 or 4) was not associated with a higher incidence of $\mathrm{PH}$ in women [24]. Whatever the reason, patients are less likely to be satisfied with anaesthesia if they have $\mathrm{PH}[10,23]$. The etiology of PH may differ between airway devices, e.g. after an ETT it may result from direct trauma to the vocal cords causing edema [35], while the cuff in the LMA may cause compression of the laryngeal nerve [36]. It is, however, important to point out that all patients in our department receive oxygen via nasal prongs in the PACU, which may also have contributed to the symptoms of both $\mathrm{PH}$ and POST because of the high flow of dry oxygen.

Persistent symptoms can be a constraint for patients, and one cause of patient dissatisfaction. In our previous study, $10 \%$ of the patients had persistent symptoms of POST and/or PH $96 \mathrm{~h}$ after an ETT [28], which contrasts with only $3 \%$ of the women who had either POST/ $\mathrm{PH}$ after 96 hours in the present study. Thus, persistent symptoms of POST/PH after 96 hours, seem to occur in only a small number of patients and all patients were symptom-free approximately two weeks after the anaesthetic in this study. 
Research investigating gender difference in anaesthesia revealed that women have a different recovery profile than men [37]. Despite the fact that women emerged faster from general anesthesia [37,38], their Quality of Recovery was poorer than that of men. In this study, however, there seem to be no significant differences between men and women in the recovery from POST and $\mathrm{PH}$ after LMA or ETT. However, there were significant differences between the sexes in pain medication peroperatively. Men received higher dosage of opioids than women which could be due to the calculation of doses in $\mu \mathrm{g} / \mathrm{kg}$. Cortisone intravenously is known to decrease POST in the postoperative period $[39,40]$. In this study, betamethasone was used for decreasing postoperative nausea and vomiting (PONV). Bethamethasone are commonly used in women who are prone to suffer from PONV [41]. The use of betamethasone for preventing postoperative nausea may influence the development of POST.

To the best of our knowledge only Joorgensen et al. [42] have studied the location of POST as assed by the patient. One reason for not asking about the precise location of POST may be that it is difficult to explain correctly. Despite the complexity of pain localization, we did find that our patients seem to be able to localize pain in the throat. We found that more patients located the pain below the larynx after an ETT compared to an LMA, probably due to the design and shape of the cuff in the ETT [43]. Pain above the larynx, was more common after an LMA than an ETT (52\% vs. $37 \%$ ), which is likely because the LMA cuff exerts pressure on the mucosa above the larynx [18]. However, pain above the larynx after an ETT could also be caused by laryngoscopy [15].

Pain in the throat was more common when using an LMA than an ETT in women during swallowing. As far as we know, no difference between the sexes has been reported before even though the findings by Rieger et al. confirmed that pain during swallowing was more common after an LMA than an ETT [23]. There are also many patients who experienced pain in the throat in the PACU at all time, namely, during rest, swallowing and talking in this study.

The follow-up questions were asked in a non-leading but direct manor by trained personnel. Direct questioning is known to increase the number of events reported by patients, which may explain the high incidence of $\mathrm{PH}$ in our study [44]. According to Myles et al. there may be a gender difference in the ability to report postoperative symptoms, and that women may find it easier to report symptoms to a nurse than do men [45]. If this indeed was the case in the present study remains unclear.

\section{Study limitations}

One weakness of the present study is that the techniques for LMA insertion vary between individuals as this was not standardized. However, the strength of this study design is that the results reflect a real-life situation with no attempts to influence insertion of the LMA or to control the experience of the personnel in any way. We did not record coughing and bucking which can have affected the result. Finally, we did not register the analgesic consumption in the ward (inpatients) or home (out patients) and this may naturally have affected the outcomes of interest. However, although all patients had analgesic medication, these did not seem to relieve POST in all patients.

\section{Conclusions}

Our study contradicts previous studies regarding the gender difference of POST and PH following general anaesthesia. In a clinical setting where women are intubated with a smaller size ETT there were no significant difference in POST or PH between genders. Additionally, more women than men have POST when an LMA is used. This is important to know so that one can take appropriate steps to prevent the development of sore throat or hoarseness in men and women.

\section{Competing interests}

The authors declare that they have no competing interest.

\section{Authors' contribution}

Substantial contribution to conception and design (MJ, AG, UN). Acquisition of data, or analysis and interpretation of data (MJ,UN). Drafting the article or revising it critically for important intellectual content (MJ,AG, UN). Final approval of the version to be published (MJ,AG,UN).

\section{Acknowledgement}

The authors would like to thank all personnel in the anaesthesia department as well as in postoperative wards for their kind support during this study. A special thanks to the research nurses Fia Strandh and Anneli Ljunggren for their help and encouragement during the data collection.

\section{Funding}

This study was done with the support from the Research Committee, Örebro county council, Örebro, Sweden.

Received: 4 May 2014 Accepted: 14 July 2014

Published: 19 July 2014

\section{References}

1. Yu SH, Beirne OR: Laryngeal mask airways have a lower risk of airway complications compared with endotracheal intubation: a systematic review. J Oral Maxillofac Surg 2010, 68:2359-2376.

2. Biro $P$, Seifert $B$, Pasch T: Complaints of sore throat after tracheal intubation: a prospective evaluation. Eur J Anaesthesiol 2005, 22:307-311.

3. Higgins PP, Chung F, Mezei G: Postoperative sore throat after ambulatory surgery. Br J Anaesth 2002, 88:582-584.

4. Chen KT, Tzeng Jl, Lu CL, Liu KS, Chen YW, Hsu CS, Wang JJ: Risk factors associated with postoperative sore throat after tracheal intubation: an evaluation in the postanesthetic recovery room. Acta Anaesthesiol Taiwan 2004, 42:3-8.

5. Ratnaraj J, Todorov A, McHugh T, Cheng MA, Lauryssen C: Effects of decreasing endotracheal tube cuff pressures during neck retraction for anterior cervical spine surgery. J Neurosurg 2002, 97:176-179.

6. Combes X, Schauvliege F, Peyrouset O, Motamed C, Kirov K, Dhonneur G, Duvaldestin P: Intracuff pressure and tracheal morbidity: influence of filling with saline during nitrous oxide anesthesia. Anesthesiology 2001, 95:1120-1124. 
7. Stout DM, Bishop MJ, Dwersteg JF, Cullen BF: Correlation of endotracheal tube size with sore throat and hoarseness following general anesthesia. Anesthesiology 1987, 67:419-421.

8. Scuderi PE: Postoperative sore throat: more answers than questions. Anesth Analg 2010, 111:831-832.

9. Hisham AN, Roshilla H, Amri N, Aina EN: Post-thyroidectomy sore throat following endotracheal intubation. ANZ J Surg 2001, 71:669-671.

10. Lehmann M, Monte K, Barach P, Kindler CH: Postoperative patient complaints: a prospective interview study of 12,276 patients. J Clin Anesth 2010, 22:13-21.

11. Myles PS, Williams DL, Hendrata M, Anderson H, Weeks AM: Patient satisfaction after anaesthesia and surgery: results of a prospective survey of 10,811 patients. Br J Anaesth 2000, 84:6-10.

12. Farrow $S$, Farrow $C$, Soni N: Size matters: choosing the right tracheal tube. Anaesthesia 2012, 67:815-819.

13. Hu B, Bao R, Wang X, Liu S, Tao T, Xie Q, Yu X, Li J, Bo L, Deng X: The size of endotracheal tube and sore throat after surgery: a systematic review and meta-analysis. PLOS ONE 2013, 8:e74467.

14. Puyo CA, Dahms TE: Innate immunity mediating inflammation secondary to endotracheal intubation. Arch Otolaryngol Head Neck Surg 2012, 138:854-858.

15. Jaensson M, Gupta A, Nilsson UG: Gender differences in risk factors for airway symptoms following tracheal intubation. Acta Anaesthesio/ Scand 2012, 56:1306-1313.

16. Stewart SL, Secrest JA, Norwood BR, Zachary R: A comparison of endotracheal tube cuff pressures using estimation techniques and direct intracuff measurement. AANA J 2003, 71:443-447.

17. LMA instruction manual. [cited $20142^{\text {nd }}$ May]. Available from: http:// rtboardreview.com/public/web_links/legacy/LMA_Airways_Manual.pdf.

18. Brimacombe J, Holyoake L, Keller C, Brimacombe N, Scully M, Barry J, Talbutt P, Sartain J, McMahon P: Pharyngolaryngeal, neck, and jaw discomfort after anesthesia with the face mask and laryngeal mask airway at high and low cuff volumes in males and females. Anesthesiology 2000, 93:26-31.

19. Mencke T, Echternach M, Kleinschmidt S, Lux P, Barth V, Plinkert PK, Fuchs-Buder T: Laryngeal morbidity and quality of tracheal intubation: a randomized controlled trial. Anesthesiology 2003, 98:1049-1056.

20. Hara K, Maruyama K: Effect of additives in lidocaine spray on postoperative sore throat, hoarseness and dysphagia after total intravenous anaesthesia. Acta Anaesthesio/ Scand 2005, 49:463-467.

21. Maruyama K, Yamada T, Hara K: Effect of clonidine premedication on postoperative sore throat and hoarseness after total intravenous anesthesia. J Anesth 2006, 20:327-330.

22. Ebneshahidi $\mathrm{A}$, Mohseni M: Strepsils(R) tablets reduce sore throat and hoarseness after tracheal intubation. Anesth Analg 2010, 111:892-894.

23. Rieger A, Brunne B, Hass I, Brummer G, Spies C, Striebel HW, Eyrich K: Laryngo-pharyngeal complaints following laryngeal mask airway and endotracheal intubation. J Clin Anesth 1997, 9:42-47.

24. Grady DM, MCHardy F, Wong J, Jin F, Tong D, Chung F: Pharyngolaryngeal morbidity with the laryngeal mask airway in spontaneously breathing patients: does size matter? Anesthesiology 2001, 94:760-766.

25. Nott MR, Noble PD, Parmar M: Reducing the incidence of sore throat with the laryngeal mask airway. Eur J Anaesthesiol 1998, 15:153-157.

26. Kloub R: Sore throat following tracheal intubation. Middle East J Anesthesiol 2001, 16:29-40.

27. Xu YJ, Wang SL, Ren Y, Zhu Y, Tan ZM: A smaller endotracheal tube combined with intravenous lidocaine decreases post-operative sore throat - a randomized controlled trial. Acta Anaesthesiol Scand 2012, 56:1314-1320

28. Jaensson M, Olowsson LL, Nilsson U: Endotracheal tube size and sore throat following surgery: a randomized-controlled study. Acta Anaesthesio/ Scand 2010, 54:147-153.

29. Brimacombe J, Berry A: Insertion of the laryngeal mask airway-a prospective study of four techniques. Anaesth Intensive Care 1993, 21:89-92.

30. An J, Shin SK, Kim KJ: Laryngeal mask airway insertion in adults: comparison between fully deflated and partially inflated technique. Yonsei Med J 2013, 54:747-751.

31. Koufman JA, Fortson JK, Strong MS: Predictive factors of cricoid ring size in adults in relation to acquired subglottic stenosis. Otolaryngol Head Neck Surg 1983, 91:177-182.

32. Burgard $G$, Mollhoff $T$, Prien $T$ : The effect of laryngeal mask cuff pressure on postoperative sore throat incidence. J Clin Anesth 1996, 8:198-201.
33. Rieger A, Brunne B, Striebel HW: Intracuff pressures do not predict laryngopharyngeal discomfort after use of the laryngeal mask airway. Anesthesiology 1997, 87:63-67.

34. Kang JE, Oh CS, Choi JW, Son IS, Kim SH: Postoperative pharyngolaryngeal adverse events with laryngeal mask airway (LMA supreme) in laparoscopic surgical procedures with cuff pressure limiting $25 \mathrm{cmH} 2 \mathrm{O}$ : prospective, blind, and randomised study. Sci World J 2014, 2014:7 pages.

35. Tanaka A, Isono S, Ishikawa T, Sato J, Nishino T: Laryngeal resistance before and after minor surgery: endotracheal tube versus Laryngeal Mask Airway. Anesthesiology 2003, 99:252-258.

36. McHardy FE, Chung F: Postoperative sore throat: cause, prevention and treatment. Anaesthesia 1999, 54:444-453.

37. Buchanan FF, Myles PS, Cicuttini F: Effect of patient sex on general anaesthesia and recovery. Br J Anaesth 2011, 106:832-839.

38. Buchanan FF, Myles PS, Leslie K, Forbes A, Cicuttini F: Gender and recovery after general anesthesia combined with neuromuscular blocking drugs. Anesth Analg 2006, 102:291-297.

39. Bagchi D, Mandal MC, Das S, Sahoo T, Basu SR, Sarkar S: Efficacy of intravenous dexamethasone to reduce incidence of postoperative sore throat: $A$ prospective randomized controlled trial. J Anaesthesiol Clin Pharmacol 2012, 28:477-480.

40. Thomas S, Beevi S: Dexamethasone reduces the severity of postoperative sore throat. Can J Anaesth 2007, 54:897-901.

41. Apfel CC, Philip BK, Cakmakkaya OS, Shilling A, Shi YY, Leslie JB, Allard M, Turan A, Windle P, Odom-Forren J, Hooper VD, Radke OC, Ruiz J, Kovac A: Who is at risk for postdischarge nausea and vomiting after ambulatory surgery? Anesthesiology 2012, 117:475-486.

42. Joorgensen LN, Weber M, Pedersen A, Munster M: No increased incidence of postoperative sore throat after administration of suxamethonium in endotracheal anaesthesia. Acta Anaesthesiol Scand 1987, 31:768-770.

43. Loeser EA, Orr DL 2nd, Bennett GM, Stanley TH: Endotracheal tube cuff design and postoperative sore throat. Anesthesiology 1976, 45:684-687

44. Harding CJ, MCVey FK: Interview method affects incidence of postoperative sore throat. Anaesthesia 1987, 42:1104-1107.

45. Myles PS, Hunt JO, Moloney JT: Postoperative 'minor' complications. Comparison between men and women. Anaesthesia 1997, 52:300-306.

doi:10.1186/1471-2253-14-56

Cite this article as: Jaensson et al:: Gender differences in sore throat and hoarseness following endotracheal tube or laryngeal mask airway: a prospective study. BMC Anesthesiology 2014 14:56.

\section{Submit your next manuscript to BioMed Central and take full advantage of:}

- Convenient online submission

- Thorough peer review

- No space constraints or color figure charges

- Immediate publication on acceptance

- Inclusion in PubMed, CAS, Scopus and Google Scholar

- Research which is freely available for redistribution 